\title{
Study of Flavonoid and Antioxidant Activity of Saponaria officinalis L. that Occurs in Buryatia
}

\author{
Galina Batoevna Endonova, Tatiana Petrovna Antsupova, \\ Sesegma Dashievna Zhamsaranova and Dandar Vladimirovich Lygdenov
}

East Siberia State University of Technology and Management, 40V Klyuchevskaya ul., Ulan-Ude, Russia, 670013.

DOI: http://dx.doi.org/10.13005/bbra/1869

(Received: 26 July 2015; accepted: 19 September 2015)

\begin{abstract}
The aim was to study the flavonoid composition of Saponaria officinalis, occurring on the territory of Buryatia, and evaluation of the antioxidant activity of the extracts of the aerial organs. The highest content of total flavonoids was noted in the leaves and inflorescences of Saponaria officinalis, gathered in sparse pine forest (near the city of Ulan-Ude). By the high performance liquid chromatography (HPLC) method we conducted a qualitative and quantitative analysis of the aerial part of Saponaria officinalis (S.officinalis). In the alcoholic extraction we identified 5 compounds of aglycone and glycosidic nature; apigenin derivatives are dominant $(43.95 \mathrm{mg} / \mathrm{g})$. The highest antioxidant activity of the extracts was in the leaves and inflorescence of Saponaria officinalis collected on abandoned sites near the village. Selenginsk (Kabansky region). To maximize the extraction of antioxidants from the plant material we studied various extractants and different variants of relations plant extract : buffer solution. We chose an optimum ratio of the plant extract and buffer solution 1: 9. With increasing the concentration of the plant extract at a dilution with buffer solurion a total content of water-soluble antioxidants increased and fat-soluble - decreased.
\end{abstract}

Key words: Saponaria officinalis, flavonoids, antioxidant activity, lipids.

Recently there has been increased an interest in natural antioxidants and to their use in food and medicine. Much attention is paid to the phenolic components of nature that are part of many plants. Therefore it is important to determine the content of flavonoid, which depends on the plant organs, phase of vegetation and other factors.

The plant extract contains spectrum of flavonoid compounds having an antioxidant effect. In this connection it is of interest to study and compare the antioxidant properties of plant extracts. The prospect of plant sources as

\footnotetext{
* To whom all correspondence should be addressed.
}

antioxidants sources is that it is a renewable raw material, which can be used for continuous production of biologically active substances.

In connection with the above, the aim of the study was to determine the total flavonoid content and composition of Saponaria officinalis, occurring on the territory of Buryatia, and evaluation of the antioxidant activity of the extracts of the aerial organs.

Saponaria officinalis (Figure 1) is a perennial herbaceous plant 25 - $80 \mathrm{~cm}$ high, with strongly branched, reddish-brown, inside yellowish, thick as a finger rhizome. Stem is ribbed, branching at the top. The leaves are opposite, oblong, dark green, with 3 veins and rough edge. The flowers are white or slightly pink, glossy, low odor, collected in tufts at the ends of branches. It 
blooms from May (June) to September. Saponaria officinalis is distributed in the European part of the CIS, the Caucasus, Central Asia, Western Siberia, as well as throughout Central and Southern Europe $^{1}$. In Buryatia this type has not been previously observed ${ }^{2}$. We have established the location of Saponaria officinalis in two districts of the Republic of Buryatia (near the city of UlanUde and urban settlement Selenginsk, Kabansky district), i.e. S. officinalis can be attributed to an introduction of the Buryat Republic.

In the official medical Saponaria drugs are used for liquefaction and expectoration of sputum in diseases of the respiratory tract and lungs, as well as a laxative and diuretic drug. Folk medicine used tincture of roots and leaves of Saponaria in diseases of the upper respiratory tract, gastrointestinal tract, rheumatism, various polyarthritis, psoriasis, herpes, eczema, and rhizomes of Saponaria are used in case of prostate adenoma. Decoction of the roots is used in head washing to prevent hair loss ${ }^{3}$. However, it can not be considered the use of this valuable plant exhaustive its full potential.

The roots of Saponaria officinalis contain carbohydrates, triterpene glycosides (2.520\%): saponarozid, saponarozidy A, D, etc. saporubin. Alkaloids, ascorbic acid, flavonoids: vitexin, saponarin, saponaretin are found inthe leaves $^{3-5}$.

Vegetable raw materials - aerial and underground bodies of Saponaria officinalis were collected in 2012 - 2014 years. in the phase of mass flowering. Raw materials in the form of the whole plants and certain organs (inflorescences, leaves, stems and roots) were dried in natural conditions to the air-dry state, packed in paper bags and stored in a cool, dark place.

To detect the groups of biologically active substances (BAS) we used common methods of qualitative analysis ${ }^{6}$. The quantitative content of total flavonoids was determined by the method developed by us earlier ${ }^{7}$. Our results show that the optimum parameters for obtaining extracts from the aerial parts of S. officinalis are extractant $70 \%$ ethyl alcohol, the degree of grinding of raw materials is $1 \mathrm{~mm}$, the extraction temperature - a boiling water bath, the ratio of raw materials, extractant - 1: 50, the multiplicity of the extraction 2 , the length of the I and II extraction - 60 minutes.
The total content of flavonoids in the aerial and underground parts of the plant was determined based on the luteolin.

The content of phenolic antioxidants in the samples was determined by amperometric method on the device "Color Jauza -01-AA" . As standards we used quercetin and gallic acid. Liposomal forms were prepared from egg yolk phospholipids by the extrusion method as antioxidant á - tocopherol factor was used. Manufacturing of multilayer liposomes was performed by hydration of the lipid film. The resulting liposome suspension was extruded through polycarbonate membranes with a pore diameter of $100 \mathrm{~nm}$ on a mini-extruder (AVESTIN, Canada $)^{9}$. All analises were performed in triplicate, the results were statistically processed.

\section{EXPERIMENTAL}

As a result of the overall phytochemical study we found that in the aerial part of S. officinalis, collected from different places of germination, there are flavonoids, saponins, alkaloids, tannins, vitamin C. In the article, special attention is paid to flavonoids - a group of substances with a very wide spectrum of biological actions. Determination of quantitative content of the flavonoids was performed on the plant organs (inflorescence, leaf, stem, root) and in all aerial parts, and depending on the phase of the vegetation and the site collection.

The dynamics of the accumulation of flavonoids in Saponaria officinalis, gathered in sparse pine forest (near Ulan-Ude) in different phases of the growing season, is presented in Table 1.

From these results it is clear that a higher content of flavonoids is in leaves and inflorescences of Saponaria officinalis. In the leaves the maximum content of flavonoids is in the flowering phase. The least amount of flavonoids is in the roots and stems occupy an intermediate position. To identify the type of raw material of $S$. officinalis we quantified flavonoid content also in all the aerial parts. We found that the aerial part of the plant as a whole contains a significant amount of flavonoids (more than in the inflorescences and stems). Therefore, from the viewpoint of efficient use of resources as a raw material of $\mathrm{S}$. officinalis 
Table 1. Dynamics of flavonoid accumulation in specific organs of Saponaria officinalis in different phases of the vegetation

\begin{tabular}{lccr}
\hline Plant's organs Vegetation phases & Budding phase & Flowering phase & Fructification phase \\
\hline 2012 y. & & & \\
Top part & - & $0,72 \pm 0,12$ & $0,59 \pm 0,22$ \\
Blossom clusters & - & $0,67 \pm 0,10$ & $0,47 \pm 0,15$ \\
Caulises & - & $0,57 \pm 0,16$ & $0,23 \pm 0,21$ \\
Leaves & - & $1,25 \pm 0,12$ & $0,96 \pm 0,19$ \\
Roots & - & $0,35 \pm 0,21$ & $0,18 \pm 0,25$ \\
To13 y & & & \\
Top part & $-40 \pm 0,26$ & $2,08 \pm 0,28$ & $1,74 \pm 0,35$ \\
Blossom clusters & - & $1,96 \pm 0,33$ & $1,03 \pm 0,26$ \\
Caulises & - & $0,93 \pm 0,21$ & $0,86 \pm 0,18$ \\
Leaves & $0,07 \pm 0,13$ & $1,85 \pm 0,17$ & $1,99 \pm 0,16$ \\
Roots & & $0,33 \pm 0,12$ & $0,27 \pm 0,31$ \\
2014 y. & $0,72 \pm 0,33$ & $0,62 \pm 0,37$ & \\
Top part & - & $0,57 \pm 0,44$ & $0,59 \pm 0,19$ \\
Blossom clusters & - & $0,21 \pm 0,32$ & $0,48 \pm 0,13$ \\
Caulises & - & $0,87 \pm 0,18$ & $0,16 \pm 0,25$ \\
Leaves & $0,10 \pm 0,12$ & $0,24 \pm 0,09$ & $0,75 \pm 0,31$ \\
Roots & & & $0,20 \pm 0,10$ \\
\hline
\end{tabular}

Table 2. The content of flavonoids in the plant material

\begin{tabular}{lc}
\hline S. Plant's organs & Total flavonoid \\
No. & content, \%
\end{tabular}

Sparse pine forest

\begin{tabular}{lll}
1 & Blossom clusters & $0,57 \pm 0,44$ \\
2 & Caulises & $0,21 \pm 0,32$ \\
3 & Leaves & $0,87 \pm 0,18$ \\
4 & Roots & $0,24 \pm 0,09$ \\
Abandoned sites (near vil. Selenginsk) & \\
5 & Blossom clusters with seeds & $0,53 \pm 0,17$ \\
6 & Caulises & $0,21 \pm 0,35$ \\
7 & Leaves & $0,75 \pm 0,24$ \\
8 & Roots & $0,11 \pm 0,14$ \\
\hline
\end{tabular}

Table 3. The quantitative content of flavonoid nature compounds

\begin{tabular}{|c|c|c|}
\hline Peaks & Compounds & $\mathrm{mg} / \mathrm{g}$ \\
\hline \multicolumn{3}{|c|}{ Apigenin derivatives } \\
\hline 2 & izoviteksin-7-O-glucoside & 43,95 \\
\hline 5 & izoviteksin & $\begin{array}{l}\text { trace } \\
\text { concentration }\end{array}$ \\
\hline \multicolumn{3}{|c|}{ Luteolin derivatives } \\
\hline 1 & orientin-7-O-glucoside & 1,18 \\
\hline 3 & orientin & trace \\
\hline 4 & izoorientan & $\begin{array}{l}\text { concentration } \\
\text { trace } \\
\text { concentration }\end{array}$ \\
\hline \multicolumn{2}{|c|}{ Total content: } & 45,13 \\
\hline
\end{tabular}

we can use a whole aerial part and only leaves. Total flavonoid content varied considerably over the years that appears to be due to different weather conditions.

Furthermore, the content of flavonoids was determined for samples of plants taken in two different habitats: in the sparse pine forest (near Ulan-Ude) and on abandoned sites (near vil Selenginsk).

Data for the quantitative determination of the content of flavonoids in plants collected from various habitats are shown in Table 2.

From the data in Table 2 we can conclude that the higher content of flavonoids is typical for S. officinalis samples collected in sparse pine forest.

5 compounds of aglycone and glycosidic nature: izoviteksin-7-O-glucoside, izoviteksin, orientin-7-O-glucoside, orientin, izoorientin was identified by the HPLC method (Figure 2).

The peaks of retention time: 1 - orientin7-O-glucoside, 2 - izoviteksin-7-O-glucoside, 3 orientin, 4 - izoorientin 5 - izoviteksin. Among the five identified flavonoids dominated: izoviteksin7-O-glucoside and orientin-7-O-glucoside. The results are shown in Table 3 .

The results from the Table 3 shows that the dominant nature of the flavonoid compounds 
are derivatives of apigenin (43.95 mg / g).

Plant extracts of Saponaria officinalis are rich in flavonoid compounds. It is known that phenolic compounds, and in particular, flavonoids are natural antioxidants ${ }^{10}$. Due to the antioxidant properties, they neutralize free radicals, slow and prevent the oxidation of the lipids ${ }^{11}$. In this regard, it is interesing to make an identification of the antioxidant properties of extracts of Saponaria officinalis.

Determination results of antioxidant activity (AOA) of the extracts from the individual organs of plants are presented in Table 4.

As it can be seen from the results, the highest total antioxidant activity was in the extracts
Table 4. The total content of antioxidants in the samples of Saponaria officinalis

\begin{tabular}{lr}
\hline S. Plant's organs & Antioxidant activity \\
No. & (AOA), mgig
\end{tabular}

Sparse pine forest

$\begin{array}{llc}1 & \text { Blossom clusters } & 13,66 \pm 0,02 \\ 2 & \text { Caulises } & 9,04 \pm 0,03 \\ 3 & \text { Leaves } & 13,96 \pm 0,02 \\ 4 & \text { Roots } & 5,04 \pm 0,03\end{array}$

Abandoned sites (near vil. Selenginsk)

\begin{tabular}{llc}
5 & Blossom clusters & $28,13 \pm 0,01$ \\
6 & Caulises & $10,26 \pm 0,02$ \\
7 & Leaves & $53,39 \pm 0,03$ \\
8 & Roots & $9,13 \pm 0,02$ \\
\hline
\end{tabular}

Table 5. The total content of phenolic antioxidants, depending on the breeding

\begin{tabular}{lcc}
\hline $\begin{array}{l}\text { Plant Extract: } \\
\text { buffer solution }\end{array}$ & $\begin{array}{l}\text { The total content of water- } \\
\text { soluble antioxidants, mg / g }\end{array}$ & $\begin{array}{l}\text { The total content of the fat- } \\
\text { soluble antioxidants, mg / g }\end{array}$ \\
\hline $1: 9$ & 14,0 & 147,5 \\
$1: 4$ & 15,0 & 73,8 \\
$1: 3$ & 28,3 & 29,2 \\
$1: 1$ & 32,8 & 36,0 \\
\hline
\end{tabular}

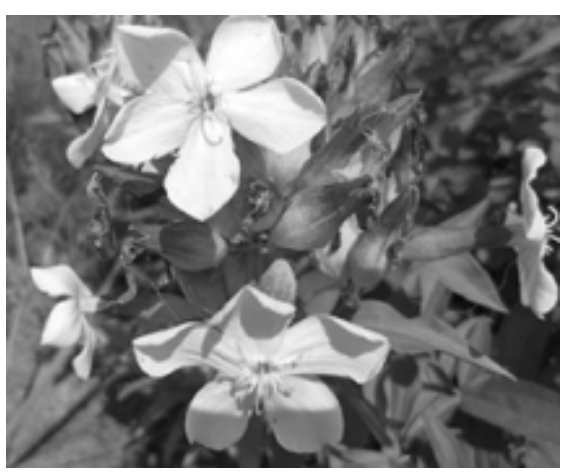

Fig. 1. Saponaria officinalis

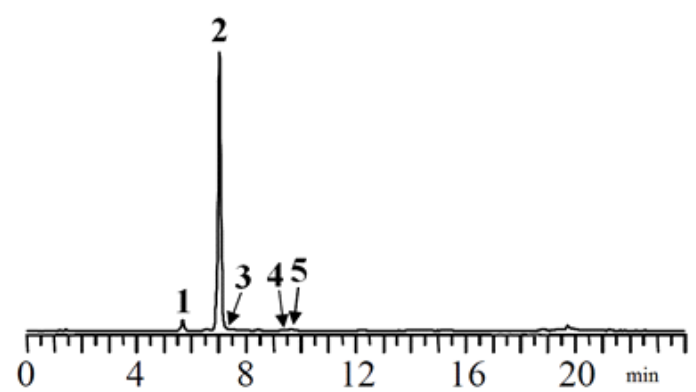

Fig. 2. The chromatogram of the flavonoid compounds of the top part $S$. officinalis of leaves and inflorescences of Saponaria officinalis collected on abandoned sites near village Selenginsk. The maximum content of the antioxidants was in the extracts of the leaves.

Based on the data for further research leaves of Saponaria officinalis collected on abandoned sites near village Selenginsk were taken.

To maximize the extraction of antioxidants from the plant material, we studied various extractants and different ratios of plant extract options : buffer solution (Table 5).

The presented results show that with increasing the concentration of plant extract, the total content of water-soluble antioxidants increased and fat-soluble - decreased. At a dilution of the extract 1: 9 total antioxidant activity of the fat-soluble antioxidants was the highest.

The effectiveness of the antioxidant therapy depends on the targeted delivery of the antioxidants to the cells. For thier transport in the small doses an optimal solution is the use of nanocapsules. With the help of nano-capsules the shelf life of drugs can be significantly extended, to prolong their action or to localize in certain organs, 
tissues or cell - target, to protect against adverse external influences, and in addition, this process enables the controlled release of drugs from the dosage form.

Liposomes can be one of the nanoencapsulated drugs, providing targeted delivery of the drugs to the target organ. Liposomes are being considered as a promising formulation for the delivery of biologically active substances to cells and tissues, as it is evidenced by many studies ${ }^{12}$.

During our work we obtained liposomes with inclusion of water-soluble and fat-soluble antioxidants. It is known that if the incorporation of hydrophobic compounds in liposomes is due to the incorporation into the phospholipid bilayer, so in the case of hydrophilic substances they are located in the aqueous core - the cavity. We have found that the total content of the liposomal form of water-soluble antioxidants averaged $27 \mathrm{mg} / \mathrm{g}$, and practically does not depend on dilution, and the total content of the liposomal form of fat-soluble antioxidants depended upon dilution and showed its maximum value of $63 \mathrm{mg} / \mathrm{g}$ in a ratio of vegetable extract: Buffer solution 1: 9. The findings call for the further studies to evaluate the biologica effectiveness of the derived forms. Perhaps corpuscular structure of the liposomes does not determine the synergistic effects in vitro, which can be detected by the release of the structures in vivo. Without a doubt, the total antioxidant will be implemented in different environments, and therefore, in different cell structures.

\section{CONCLUSIONS}

1. The highest content of the total flavonoids was noted in leaves and inflorescences of Saponaria officinalis, gathered in sparse pine forest (near Ulan-Ude).

2. By the HPLC method in ethanol extracts 5 compounds of aglycone and glycosidic nature were identified; apigenin derivatives are dominant $(43.95 \mathrm{mg} / \mathrm{g})$.
3. The highest antioxidant activity of the extracts was in leaves and inflorescence of Saponaria officinalis collected on abandoned sites (vil. Selenginsk). With increasing the concentration of plant extract the total content of water-soluble antioxidants increased and fat-soluble decreased. We chose an optimum ratio of the plant extract and buffer solution 1: 9 .

\section{REFERENCES}

1. Flora of Siberia., Nauka. Sib. Enterprise RAS, 1997; 6: 470.

2. Anenhonova, O.A., Guide to the Plants of Buryatia. Ulan-Ude: Institute of General and Experimental Biology, 2001; 670.

3. Plant resources of the USSR: Flowering plants, their chemical composition, the use. Family Caprifoliaceae-Plantaginaceae. L .: Science, 1990; 328.

4. Andrzejewska, E., The method of determination of saponins in certain foods. - Rocz. Railway stations Rus. Zaktan. Hig., 1975; 26(1): 87-92

5. Pasich, B., Triterpenoid compounds in plant materials. PhD thesis, 1961.

6. Grinkevich, N.I. \& Safronich, L.N., Chemical analysis of medicinal plants M .: Higher School. 1983; 176.

7. Endonova, G.B. \& Antsupova, T. P., Bulletin of the East Siberian State University of Technology and Management, 2014; 1: 89-92

8. Natural antioxidants. The content in foods and their influence on health and human aging $\mathrm{M}$.: Publishing house "TrasLit”, 2009; 212.

9. Pat. RF 2308940. A method for producing liposomes having immunocorrective and hepatoprotective action, 2006.

10. Kahkonen, M.P., Antioxidant Activity of Plant Extracts Containing Phenolic Compounds, $J$. Agric. Food Crem., 1999; 47: 3954-3962.

11. Karpova, E.A., Khramova, E.P. \& Fershalova, T.D., Chemistry of plant raw materials, 2009; 2: $105-110$.

12. Seifula, R.D., Pharmacology liposomal formulations (experimental and clinical) $\mathrm{M}$.: Globe Continental 2010; 241. 